\title{
GC--MS analysis of Japanese Banana Flower without pollen and Pollen \\ Yuqing Liang ${ }^{1, \mathrm{a}}$,Yuanmin Wang ${ }^{2, \mathrm{~b}}$,Liubo Yang ${ }^{2, \mathrm{~b}}$, Hongmei $\mathrm{Wu}^{2, \mathrm{~b}}$, Xiangpei Wang $^{3, c}$ \\ ${ }^{1,2,3}$ Department of Pharmacognosy, Guiyang College of Traditional Chinese Medicine, 50, Nanming District, Guiyang City, Guizhou Province, Guiyang 550002, PR China \\ aemail:1083741909@qq.com; \\ bemail:1143319279@qq.com,799550947@qq.com; \\ cemail:wxp0123@126.com
}

\begin{abstract}
Keyword:Japanese banana flower without pollen; Japanese banana pollen; volatiles; gas chromatography-mass spectrometry (GC-MS)

Abstract: The Japanese banana flower and pollen were analyzed by gas chromatography-mass spectrometry (GC-MS) technique, coupled with head-space solid micro-extraction (HS-SPME). The relative percentage of compounds were measured by retention index and peak area normalization method. A total of 48 volatiles were identified in Japanese banana flower without pollen. Forty volatiles were identified in Japanese banana pollen. There were 20 compounds we found in both flower and pollen, accounting for $34.35 \%$ and $49.99 \%$ of thetotal volatiles, respectively. It can be seen the compounds between flowers andpollen were different apparently. This is the first ever report revealing the differences of volatile components between the Japanese banana flower without pollen and pollen.
\end{abstract}

\section{Introduction}

Musa basjoo Sieb. et Zucc. is originating in Japan, the Ryukyu Islands. In China, it is mainly distributed in subtropical regions, such as Guizhou,Guangdong, Guangxi,Hainan,Sichuan,Yunnan and Taiwan[1]. Japanese banana flower is the flower of Musa basjoo Sieb.et Zucc. In Yunnan, Japanese banana flower is one of the more popular food and many people like to cook with Japanese banana flower [2-3]. Modern researches show that the dried Japanese banana flower have apparent effective to treat cerebral hemorrhage[4]. Both Japanese banana flowers and pollen all have aromatic smell, but the smell of pollen is stronger than flower's. The reason why the aromatic smell of pollen is stronger than flower's is unexplained, and there is no any relevant reports about that.Volatile oil is a key of aromatic smell, so the research on volatile components is very important.In this paper, the flower and pollen of Japanese banana were analysis by gas chromatography-mass spectrometry (GC-MS) with solid-phase micro extraction (SPME). Then, the comparison among the flower and pollen of Japanese banana was made. A comparative analysis on why the aromatic smell of pollen is stronger than flower's of Japanese banana also evaluated. This study could provide a scientific basis for the further development and utilization of the flower and pollen of Japanese banana.

\section{Materials and methods}

\section{Plant materials}

The flower without pollen and pollen of Japanese banana were collected from Yunnan in May, 2015 and further identified by Dr. X.P. Wang, Department of Pharmacognosy Guiyang College of Traditional Chinese Medicine, P. R. China. All voucher specimens were deposited in the Department of Pharmacognosy, Guiyang College of Traditional Chinese Medicine, P.R. China. The pollen was separated from the flowers, and they were placed in a cool, dry environment $\left(20^{\circ} \mathrm{C}\right)$ to dry naturally.

\section{Solid-phase micro extraction procedure}

The flower without pollen small pieces and pollen of Japanese banana were accurately weighed $(6.0 \mathrm{~g})$ and placed into $25-\mathrm{mL}$ sample vials from Supelco (Bellefonte, USA), respectively. Then, a 
2cm-50/30um DVB-CAR-PDMS Stable Flex fiber (Bellefonte, USA) was used to the headspace above the samples for extracting $40 \mathrm{~min}$ under about $100{ }^{\circ} \mathrm{C}$. then the extraction head was removed from sample vials and immediately inserted onto the GC injection port. The SPME fiber head was hung over the vial for 3 min and then directly desorbed and analyzed.

\section{Gas Chromatography-Mass Spectrometry}

The analyses of gas chromatography was performed on a Hewlett-Packard 6890GC-5973C MSD (Agilent, Palo Alto, CA, U.S.A.) using a ZB-5MSi (5\%phenyl-95\%dimethylpolysiloxane) fused silica capillary column $(30 \mathrm{~m} \times 0.25 \mathrm{~mm} \times 0.25 \mathrm{~mm})$. The oven temperature was programmed as follows: held at $40^{\circ} \mathrm{C}$ for $2 \mathrm{~min}$, adjusted to $270^{\circ} \mathrm{C}$ at a rate of $5^{\circ} \mathrm{C} / \mathrm{mi}$,run $48 \mathrm{~min}$, The injector temperature was $250^{\circ} \mathrm{C}$. High-purity helium $(99.999 \%)$ was used as the carrier gas at a flow rate of $1.0 \mathrm{ml} / \mathrm{min}$ with splitless injection.

The mass spectrometer was fitted with an electron ionization source operated at $70 \mathrm{eV}$. The source temperature was $230^{\circ} \mathrm{C}$, and the interface temperature was $280^{\circ} \mathrm{C}$ with a solvent delay of 1.5 min. The emission current was $34.6 \mu \mathrm{A}$, and the multiplier voltage was $1294 \mathrm{~V}$. Mass spectra were recorded from $\mathrm{m} / \mathrm{z} 29-450 \mathrm{amu}$ in the full scan mode. Volatile compounds were identified by comparison of mass spectra of the analytes with those of authentic standards from the NIST2005 and Wiley275 libraries. The instrument Chemstation data processing system was used to determine the relative concentrations of the analytes by the peak area normalization method.

\section{Determination of Retention Index}

After mixing the chromatography on n-alkanes $\left(\mathrm{C}_{6}-\mathrm{C}_{26}\right)$ and the same amount from each sample , according to the above GC chromatographic analysis conditions, the retention time was measured for each sample and n-paraffins, and then the retention indices $(\mathrm{KI})$ was calculated by formula $(\mathrm{KI}=$ $\left.100 n+100\left(t_{x}-t_{n}\right) /\left(t_{n+1}-t_{n}\right)\right)[5]$. $T_{x}$ represented the retention time of the test substance, $n$ represented the corresponding $n$-alkane carbon atom, $t_{n}$ and $t_{n+1}$ are the retention time of $n$-alkane whose number of carbon atoms in a difference of $1\left(t_{n}<t_{x}<t_{n}+1\right)$. Kovats retention indices can improve the accuracy of identification results .In the identification of aromatic oils complex component, this method got generally accepted and widely used in the international arena.

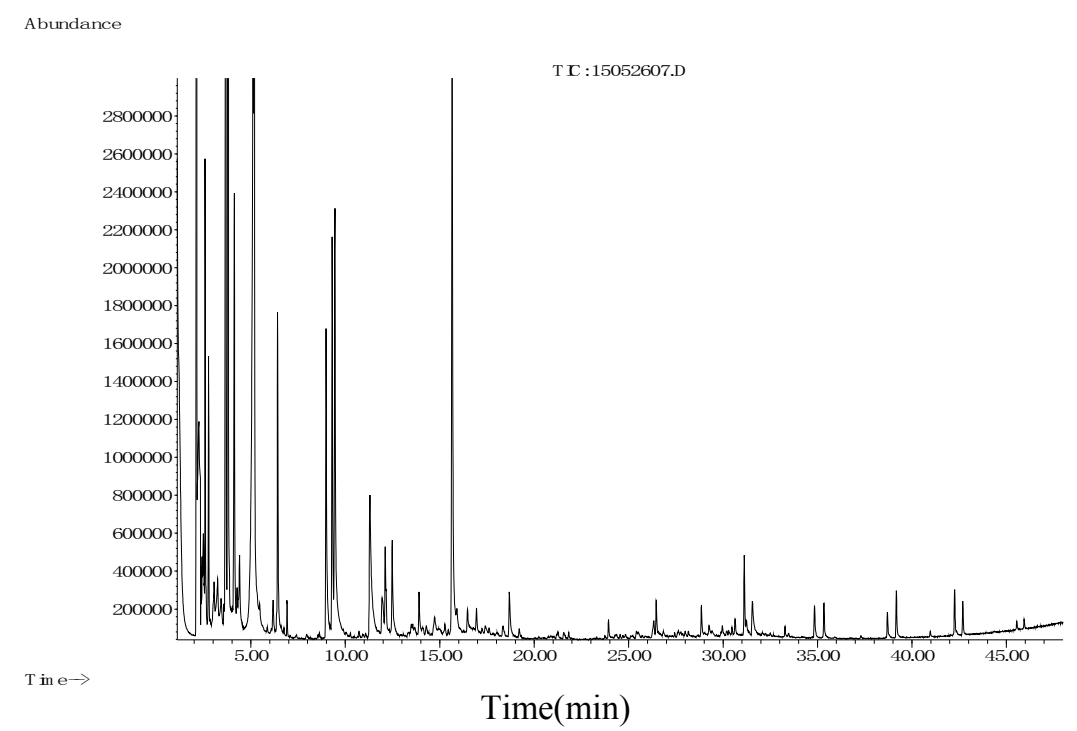

Fig1. TIC of volatile components extracted from Japanese banana flower without pollen 


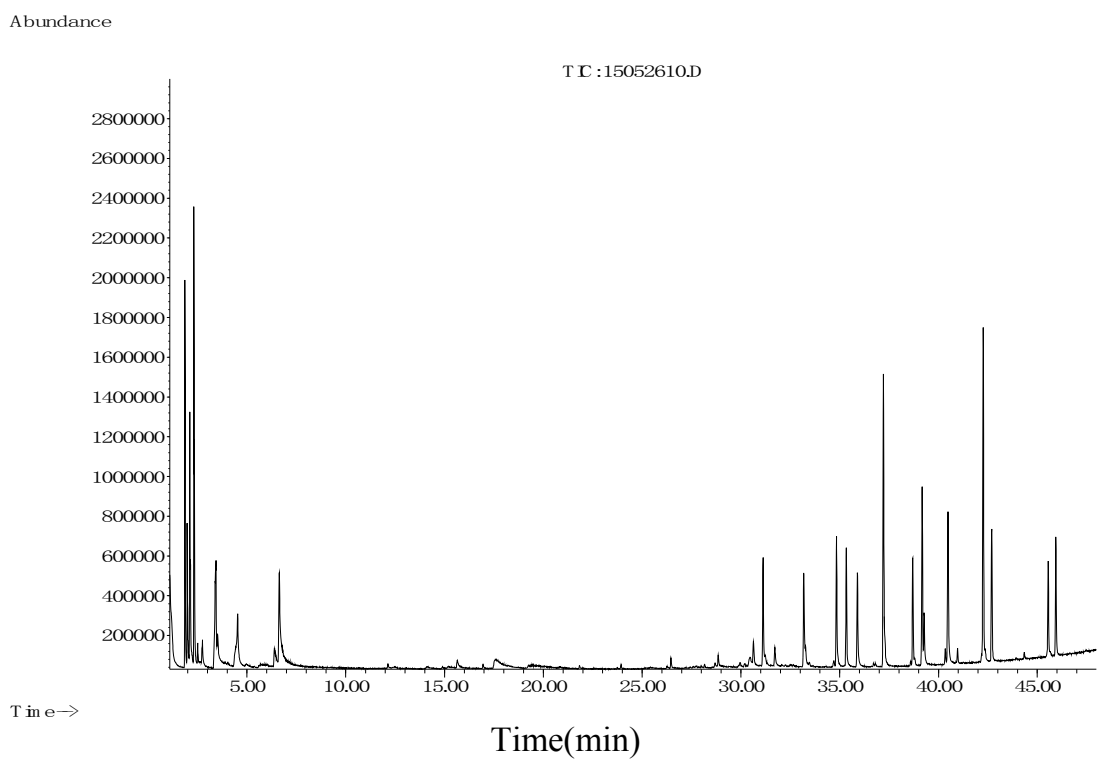

Fig 2. TIC of volatile components extracted from Japanese banana pollen

Table1.Percentages of volatile components extracted from Japanese banana flower without pollen and pollen

\begin{tabular}{|c|c|c|c|c|}
\hline \multirow[b]{2}{*}{ No. } & \multirow[b]{2}{*}{ Retention time (min) } & \multirow[b]{2}{*}{ Compound } & \multicolumn{2}{|c|}{ Percentage $(\%)$} \\
\hline & & & Flower & Pollen \\
\hline 1 & 1.97 & Ethanal & - & 2.336 \\
\hline 2 & 2.10 & $\mathrm{EtOH}$ & - & 4.691 \\
\hline 3 & 2.25 & Methanol & 5.494 & - \\
\hline 4 & 2.31 & Dimethyl sulfide & 2.19 & 8.103 \\
\hline 5 & 2.48 & Acetone & 0.46 & - \\
\hline 6 & 2.50 & 2-Methyl-propanal & 1.789 & 0.312 \\
\hline 7 & 2.62 & Methyl acetate & 0.065 & - \\
\hline 8 & 2.75 & 2,3-Butanedione & - & 0.614 \\
\hline 9 & 3.05 & 2-Butanone & 0.342 & - \\
\hline 10 & 3.42 & 2-Methyl-propanol & 0.282 & - \\
\hline 11 & 3.43 & Acetic acid & - & 4.672 \\
\hline 12 & 3.52 & 2-Methylbutanal & 17.753 & 1.542 \\
\hline 13 & 3.66 & 3-Methylbutanal & 9.907 & - \\
\hline 14 & 4.12 & 2-Pentanone & 3.506 & - \\
\hline 15 & 4.40 & 2-Pentanol & 0.539 & - \\
\hline 16 & 4.53 & 3-Hydroxy-2-butanone & - & 3.45 \\
\hline 17 & 5.11 & 3-Methyl-1-butanol & 10.653 & - \\
\hline 18 & 5.18 & 2-Methyl-1-butanol & 6.826 & - \\
\hline 19 & 5.46 & 2-Hydroxy-3-butanone & 0.154 & - \\
\hline 20 & 6.18 & 2-Hexanone & 0.358 & - \\
\hline 21 & 6.36 & Octane & 0.081 & - \\
\hline 22 & 6.41 & Hexanal & 2.679 & - \\
\hline 23 & 6.64 & 2,3-Butanediol & - & 5.324 \\
\hline 24 & 6.75 & 2-Octene & 0.047 & - \\
\hline 25 & 8.98 & 2-Heptanone & 3.42 & - \\
\hline 26 & 9.31 & Heptanal & 3.626 & - \\
\hline 27 & 9.45 & 2-Heptanol & 5.771 & - \\
\hline 28 & 11.30 & Benzaldehyde & 3.374 & - \\
\hline 29 & 12.11 & 2-Amylfuran & 0.759 & - \\
\hline 30 & 12.48 & Octanal & 1.106 & - \\
\hline 31 & 13.91 & trans-beta-Ocimene & 0.551 & - \\
\hline
\end{tabular}




\begin{tabular}{|c|c|c|c|c|}
\hline 32 & 14.10 & 1-Ethyl-2-formyl pyrrole & - & 0.317 \\
\hline 33 & 14.89 & 2,6-diethyl-Pyrazine & - & 0.124 \\
\hline 34 & 15.21 & 3-Ethyl-2,5-dimethylpyrazine & - & 0.263 \\
\hline 35 & 15.27 & 2-Nonanone & 0.099 & - \\
\hline 36 & 15.65 & Nonanal & 7.844 & 0.421 \\
\hline 37 & 17.58 & $\begin{array}{l}\text { 2,3-Dihydro-3,5-dihydroxy-6- } \\
\text { Methyl-4H-pyran-4-one }\end{array}$ & - & 1.987 \\
\hline 38 & 18.69 & Decanal & 0.677 & - \\
\hline 39 & 19.21 & beta-Cyclocitral & 0.111 & - \\
\hline 40 & 21.26 & Tridecane & 0.063 & - \\
\hline 41 & 23.93 & Tetradecane & 0.184 & 0.105 \\
\hline 42 & 26.33 & beta-ionone & 0.275 & - \\
\hline 43 & 26.46 & Pentadecane & 0.489 & 0.272 \\
\hline 44 & 28.69 & 1-Hexadecene & - & 0.104 \\
\hline 45 & 28.85 & Hexadecane & 0.3 & 0.285 \\
\hline 46 & 30.63 & 8-Heptadecene & 0.152 & 0.885 \\
\hline 47 & 31.12 & Heptadecane & 0.755 & 2.94 \\
\hline 48 & 31.24 & Pristane & 0.167 & 0.387 \\
\hline 49 & 31.72 & Methyl myristate & - & 0.648 \\
\hline 50 & 33.18 & Ethyl myristate & - & 2.926 \\
\hline 51 & 33.27 & Octadecane & 0.088 & 0.681 \\
\hline 52 & 33.46 & Phytan & 0.029 & \\
\hline 53 & 34.70 & (Z)-9,17-Octadecadienal & - & 0.208 \\
\hline 54 & 34.84 & 1-Nonadecene & 0.368 & 3.837 \\
\hline 55 & 35.33 & Nonadecane & 0.381 & 3.21 \\
\hline 56 & 35.89 & Methyl palmitate & - & 3.025 \\
\hline 57 & 37.21 & Ethyl palmitate & - & 8.87 \\
\hline 58 & 38.69 & 10-Heneicosene & 0.246 & 2.925 \\
\hline 59 & 39.17 & Heneicosane & 0.484 & 4.79 \\
\hline 60 & 39.27 & Methyl linolenate & - & 1.618 \\
\hline 61 & 40.34 & Ethyl linoleate & - & 0.446 \\
\hline 62 & 40.48 & Ethyl linolenate & - & 5.078 \\
\hline 63 & 40.97 & Docosane & 0.05 & 0.403 \\
\hline 64 & 42.26 & (Z)-9-Tricosene & 0.451 & 9.3 \\
\hline 65 & 42.69 & Tricosane & 0.33 & 3.717 \\
\hline 66 & 44.34 & Tetracosane & - & 0.158 \\
\hline 67 & 45.55 & Z-12-Pentacosene & 0.071 & 2.657 \\
\hline 68 & 45.94 & Pentacosane & 0.087 & 3.274 \\
\hline
\end{tabular}

\section{Results and Discussion}

The volatile components were isolated and identified by experimental methods and experimental conditions. The relative percentage of compounds were measured by retention index and peak area normalization method.The total ion chromatogram of Japanese banana flower without pollen and pollen of are shown in Fig. 1 and Fig. 2, and the corresponding volatile compounds are listed in Table 1 . A total of 68 volatile components were identified from Japanese banana flower without pollen and pollen by GC-MS technology. It is shown that 48 volatile components were identified from the Japanese banana flower without pollen in Table 1.There were some components with high concentrate relatively, for example, 2-methylbutanal (17.753\%), 3-methyl-1-butanol(10.653\%), nonanal $(7.844 \%)$, 2-heptanol $(5.771 \%)$,etc. It was also shown that 40 volatile components were identified from the Japanese banana flower without pollen in Table 1.There are some components with high concentrate relatively, such as ethyl palmitate( $(8.87 \%)$, dimethyl sulfide( $8.103 \%)$, 2,3-butanediol(5.324\%), ethyl linolenate(5.078\%)and so on.

As shown in Table 1, 20 components were found both in flower and pollen, accounting for $34.35 \%$ and $49.99 \%$, respectively. Decanal and cyclocitral were unique to flowers and pyrrole and 
pyrazine were pollen-specific. The content of aldehydes were higher in flower and esters had a higher content in pollen.

It was found that 2-methylbutyraldehyde has a chocolate flavor[6]. In food industry, nonanal is a food additive, and in terms of chemical process it can be used as intermediates in organic synthesis, spices raw materials, and rubber accelerator [7]. Maybe nonanal and 2-methylbutyraldehyde are the reason why Japanese banana flower without pollen have aroma. Ethyl palmitate is the main volatile components in pollen. It showed a weak wax, fruity and cream aroma[13].Therefore, the ethyl palmitate is likely to be a major contributor to the aroma of pollen.In addition, it was found ethyl palmitate may be an active ingredient in tagging Plutella[14].

\section{Conclusion}

In this paper, a total of 68 volatile components from Japanese banana flower without pollen and pollen were isolated and identified by headspace solid phase microextraction and gas chromatography - mass spectrometry. In Japanese banana flowers without pollen,48 components were identified, and the main components were 2-methylbutanal, 3-methyl-1-butanol,nonanal, 2-heptanol. In Japanese banana pollen only 40 components were identified,and the main components were ethyl palmitate, dimethyl sulfide, 2,3-butanediol, ethyl linolenate. It was found that 20 components were both in flower without pollen and pollen, but the main components from them were different.It can be seen the compounds between flowers and pollen were different apparently.The difference of the main components between flowers and pollen was possible leading to different flavor.This work could provide a reference for the further development of Japanese banana flower and pollen .

\section{References}

[1] Editorial Committee of Flora of China of Chinese Academy of Sciences:Flora of China.Science Press,2004:235.(In Chinese)

[2] J.R.Zhang: Diet Culture of Southern Yunnan Japanese Banana. Western Development, 2006(8): 49-50. (In Chinese)

[3] L.Zhou:Medicinal and Diet of Japanese Banana Flower. Flower Pot:Flowers \& Horticulture, 2003(9): 42. (In Chinese)

[4] Institutum Botanicum Kunmingense Academiae Sinicae Edita. 'FloraYmma nnica',Tomus 2. Beijing:Science Press, 1979.

[5] C.X.Wu,Y.J.Xing,N.F.Cao,at el:Research of volatile components of Elaeagnus root from Yichang by HS-SPME-GC /MS.Chinese Journal of Experi mental Traditional Medical Formulae,2010,16(10):53.(In Chinese)

[6] M.L.Lin,Q.Q.Xu,H.L.Song,P.Li,J.Xiong and S.S.Li: Isolation and Identification of aroma active compounds of Yeast Extract. Food Science.2013,34(8):259-262.(In Chinese)

[7] Y.M.Gao,X.L.Wang,Y.Gong,H.Wang, and Q.Liao:Headspace gas chromatography-mass spectrometry for coated fabric of fragrances nonanal. Analytical Instruments. 2011,17(6):32-35.(In Chinese)

[8] Y.Q.Zhong and Y.B.Xia:SPME-GC-MS analysis of flavor components in hot pepper sauce of various fermentation ways.Food Science and Technology.2012,37(8):271-275.(In Chinese)

[9] J.H.Ding,L.H.Liu and S.W.Liu:Analysis of biological activity and active components about Polygoni aviculare against Plutella. Jiangsu Agricultural Sciences.2011.39(4):112-113.(In Chinese) 